\title{
Smartphone Enabled Advanced Vehicle Tracking System
}

\author{
Swapnali Mohanrao Kumbhar \\ Department of Electronics \& Telecommunication \\ Annasaheb Dange College of Engineering and \\ Technology, Ashta \\ Shivaji University, Kolhapur,Maharashtra, India
}

\author{
Sunita Sunil Shinde \\ Department of Electronics \& Telecommunication \\ Annasaheb Dange College of Engineering and \\ Technology, Ashta \\ Shivaji University, Kolhapur,Maharashtra, India
}

\begin{abstract}
Today's current worldwide circumstances, the leading question in every persons mind taking into account is the ever rising increase of issues on vehicle security and safety. The only thought haunting in everyone's mind is when they will be able to move freely on the road even in odd hours without worrying. At the same time, Smartphone's are constantly increasing their connection capabilities. The continuous improvement of cellular networks, that can now provide high speed data communications, makes it possible to consider them for safety related services as well as for information and entertainment. This opens the way to the use the Smartphone's for communication. In the existing systems security lock and alarm is implemented in a car. But such facilities are not able to compete the requirements of users and will not provide the security. So, authorized user needs a security system along with fully automated tracking which will fulfill the requirements of the owners /users which give better results. Users will be able to monitor a moving vehicle on demand using the Smartphone application. In order to show the achievability and efficiency of the system, this paper presents experimental results of the vehicle tracking system and some experiences on practical implementations.
\end{abstract}

\section{General Terms}

Vehicle security and tracking using Smartphone enabled app.

\section{Keywords}

Vehicle Tracking Smartphone App, GPS, GSM/GPRS, Arduino UNO Controller

\section{INTRODUCTION}

The real - time need of vehicle tracking is in shipping industries and transportation systems because user/owner wanted to know where each vehicle was at any given time. In some industries delivery of product at exact time is very essential condition demanding from the customers, to know the exact timing of delivery of product authorized user can use Smartphone based vehicle tracking system which will help to provide actual location of the vehicle.

The system design provides an intelligent way of correlation between the Vehicle and Smartphone. The main reason of this work is to provide security of the users. [1] Here, security is provided by the smart way with the easily available and most popular device now a day and that is Smartphone. Smartphone's provides a lot of features which are effortless to handle for anybody and quite familiar with all aged users. [2] In some industries delivery of product at exact time is very essential condition demanding from the customers, to know the exact timing of delivery of product, authorized user can use Smartphone based vehicle tracking system which will help to provide actual location of the vehicle.

A Smartphone application is developed for monitoring the vehicle location on missed call as a request. The vehicle tracking system uses the GPS module to get geographic coordinates at time when GSM module inside a vehicle receives a missed call from the user. The GSM/GPRS module is used to transmit coordinates on Smartphone and update the vehicle location to a database. The Google Map is used to display the vehicle's location on the map in the Smartphone application. With the Smartphone it is straightforward to track the vehicle $24 X 7$ by adapting GPS, GSM/GPRS systems. The embedded design of the system also implies temperature detection unit, ignition control unit. All the information will be conveyed to the user server via GSM/GPRS. This information is recorded in database so user can recover the current and past status any time. [7]

\section{MOTIVATION}

Safety on road is a critical problem to address. A connected vehicle can interact with other vehicles and/or authorized person. The communication among vehicles and Internet (through Smartphone) gives us the opportunity to define a new "class" of vehicles: what it calls a Smartphone Enabled Vehicle.

Today the vehicle security is one of the major issues of our nation, such as stolen of fuel, driver drunk, accidents, stolen of vehicles, driving on incorrect path, wasting of time etc. The main objective of this thesis is to track the vehicle 24 hours by adapting the GPS, GPRS, GSM system. The system implies fuel sensor for detection for fuel, puncture detection unit, vehicle wait time detection, temperature detection, ignition control through SMS \& tracking. All the information will be conveyed to the user server via GPRS \& GSM. This information is recorded in database so user can recover the current $\&$ past status any time. Status is also conveyed on user mobile.

\section{HARDWARE USED}

The execution of the system is achieved by Arduino unit which is the heart of the system.[8] All the controlling functions, data transmitting functions are done by this unit. GSM/ GPRS module used as a medium for communication between server \& vehicle. The requirement of power supply is $12 \mathrm{~V} \mathrm{dc} / 2 \mathrm{~A}$ max, for all system. At monitoring side authorized user will receive the data of location in the form of latitude and longitude given by GPS. Tracking is also done at user mobile. (See Figure 1) 
Uno boards with version 1.0 of Arduino Software (IDE), the programming languages supported by Arduino are $\mathrm{C}$ and $\mathrm{C}++$. Here, $\mathrm{C}$ language is used for coding. The software is open-source. Arduino supports for quickly changes in coding as well as uploading of the program is very easy, there is no need of any external device for uploading program.
Satellite
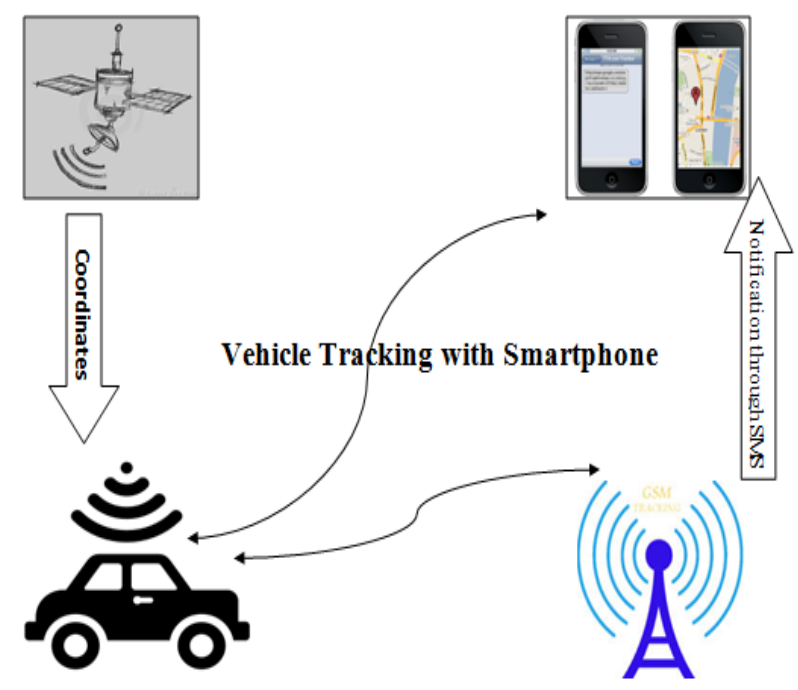

Vehicle with GPS and GSM module
Vehicle Tracking with Smartphone|

GSM Tower

\section{Fig 1: Smartphone Enabled Advanced Vehicle Tracking} System

\subsection{Arduino UNO}

"Uno" means one in Italian and was chosen to mark the release of Arduino Software (IDE) 1.0.The Uno board and version 1.0 of Arduino Software (IDE). The programming languages supported by Arduino are $\mathrm{C}$ and $\mathrm{C}++$. Here, $\mathrm{C}$ language is used for coding. The software is open-source. Arduino supports for quickly changes in coding as well as uploading of the program is very easy, there is no need of any external device for uploading program.

\subsection{GSM Modem}

GSM (Global System for Mobile communication) is digital cellular technology used for transmitting information services and transportable voice. For this work SIM900A Modem is used because of the features available in modem are excellent. It uses frequencies $900 / 1800 \mathrm{MHz}$ for working. AT Commands can be used to set the frequency bands. AT commands configure the baud rate is from 1200-115200. The modem is having internal TCP/IP stack to enable to connect with internet via GPRS.

\subsection{GPS Modem}

GPS (Global Positioning System) is used as a navigation system by civilians. On the ground, GPS receiver holds its position by getting information from minimum three satellites. The result is available in the form of geographic position (latitude and longitude). These coordinates guide the user for driving or walking.

\subsection{LCD Display}

Liquid crystal display is used to display all the results on a screen in vehicle. LCD (Liquid Crystal Display) screen is an electronic display module and find a wide range of applications. A 16x2 LCD display is very basic module and is very commonly used in various devices and circuits. These modules are preferred over seven segments and other multi segment LEDs. The reasons being: LCDs are economical; easily programmable; have no limitation of displaying special $\&$ even custom characters (unlike in seven segments), animations and so on.

\section{SYSTEM FLOW}

In the Smartphone enabled advanced vehicle tracking system, the person whose unique and valid mobile number is registered in the system considered as an authorized person, who will interact with the vehicle tracking system.

Then, only authorized person have right to request for vehicle location by giving a missed call to the system. On receiving a missed call, GPS receiver collects the coordinates from the satellite in the form of latitude and longitude.[13] Then, these coordinates send towards the GSM module. ${ }^{13}$ Once the GSM module receives the coordinates from GPS then coordinates will send to the authorized person's Smartphone. After receiving coordinates in the form of text message on the authorized person's Smartphone, coordinates get extracted in the vehicle tracking app and exact location of vehicle is displayed.

This system simultaneously works on the other security issues which occurred at any instant of time such as accident detection, puncture detection, fuel status and ignition control etc. When there will be a situation like accident, with the help of infra red sensors system detect a distance between vehicles and gives an alert buzzer with displaying message as "Keep safe distance" on liquid crystal display (LCD).[13] System check the fuel level and displays the status of fuel level in the form of high or medium or low. When vehicle gets started ignition control unit (ICU) comes into picture, ICU send the message to the authorized person as a status of vehicle either $\mathrm{ON}$ or OFF.

Android mobile application is developed on Eclipse. Android is now the most used mobile operating system in the world. Android now has more users, more phones and more tablets worldwide than any other mobile operating system. The Google Play app store has been growing at breakneck speed and with almost as many apps as the Apple app store. 


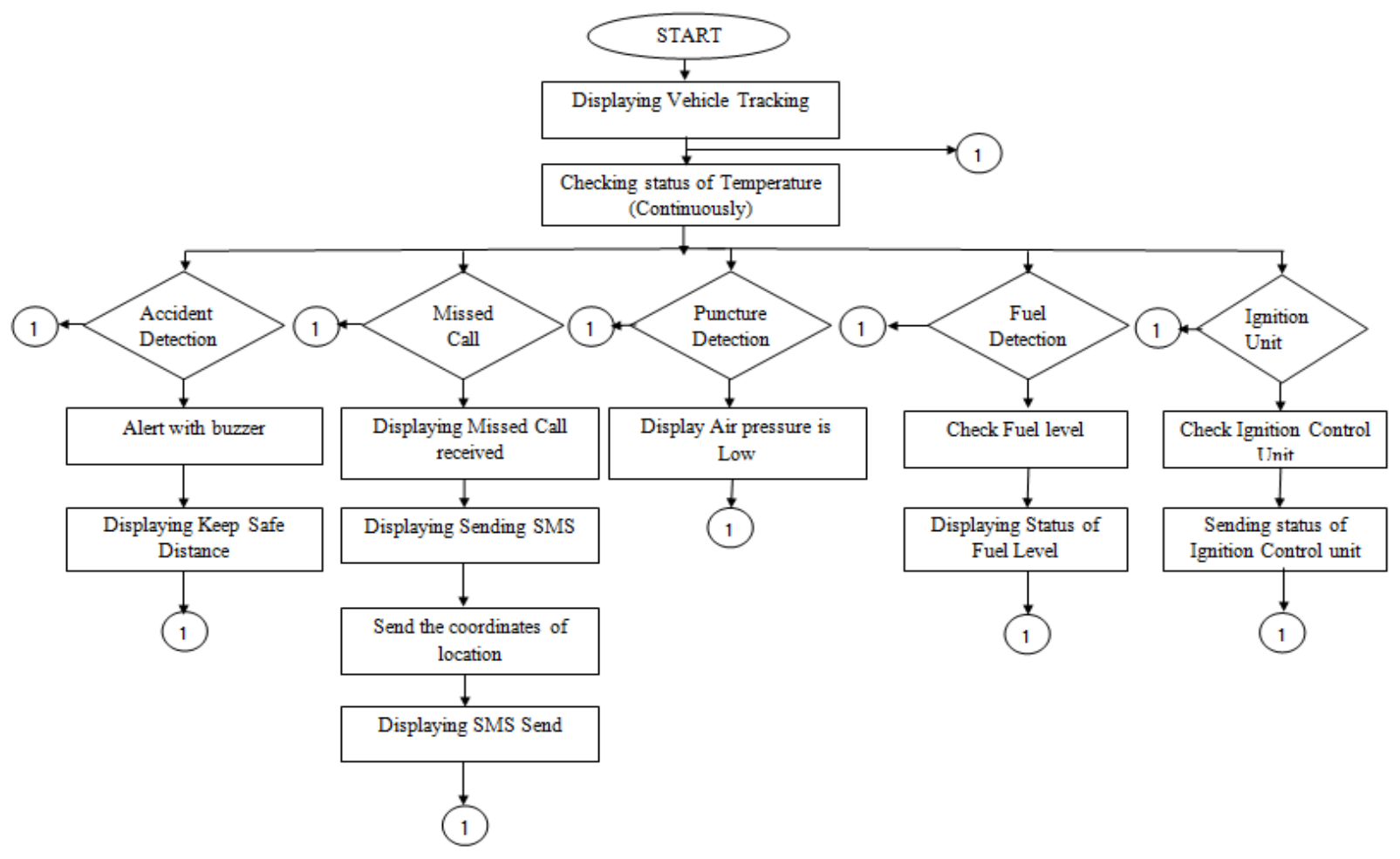

Fig.2 Design flow of Smartphone Enabled Advanced Vehicle Tracking System

\section{CONCLUSION}

In this paper, authors have presented a mechanism of Smartphone Enabled Advanced Vehicle Tracking System providing exact location of the vehicle by giving a one missed call. This system can help to identify the location of the vehicle at any time $24 \times 7$. System gives approximate $95 \%$ accuracy.

In future Smartphone Enabled Advanced Vehicle Tracking System will provide "Smart vehicle drive" that is Internet on Vehicle. The rising concept of Smart vehicle drive is based on the concept of Internet on Vehicle.

\section{RESULTS}

Observations and results are discussed in following parts:

Part A: At the vehicle side

Part B: At the authorized user side

Part C: At the monitor side

\section{Part A: At the vehicle side}

When vehicle getting started to travel then at that instant Ignition Control Unit send a SMS towards the authorized persons Smartphone that "VEHICLE TRACKING SYSTEM_ IGNITION ON DETECTED"

After that on LCD Screen which is placed inside the vehicle a message getting displayed "VEHICLE TRACKING" as shown in Fig. 3 immediately after vehicle getting started.

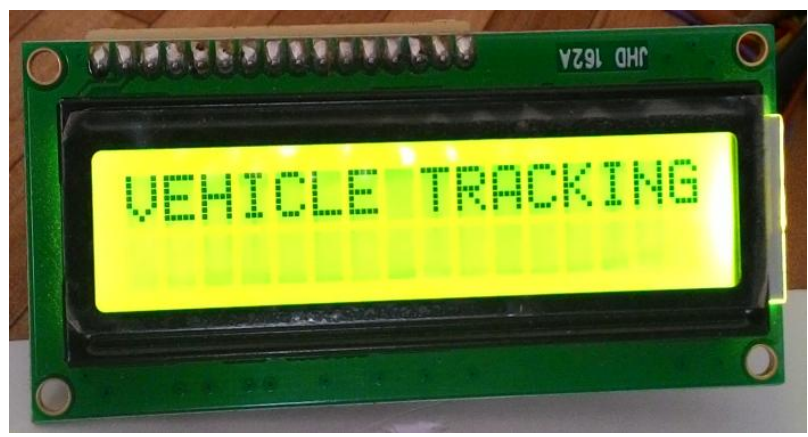

Fig. 3 VEHICLE TRACKING message on LCD display

Simultaneously temperature unit inside the vehicle start working and display the current temperature on LCD Screen as shown in Fig. 4

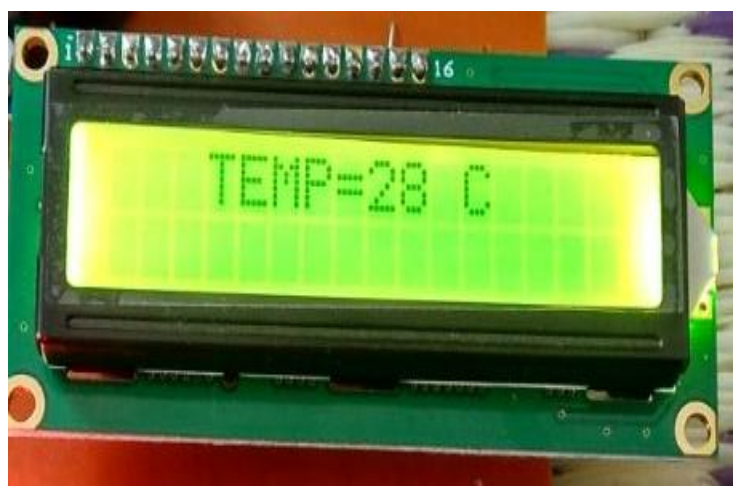

Fig. 4 Temperature Detection

Temperature detection is the only one parameter which is continuously going on till any interrupt will not occur or vehicle will not stop. 
System also provides the indication of the fuel level, when fuel level is high then message should be displayed on the LCD screen as "FUEL: HIGH" as shown in Fig.5

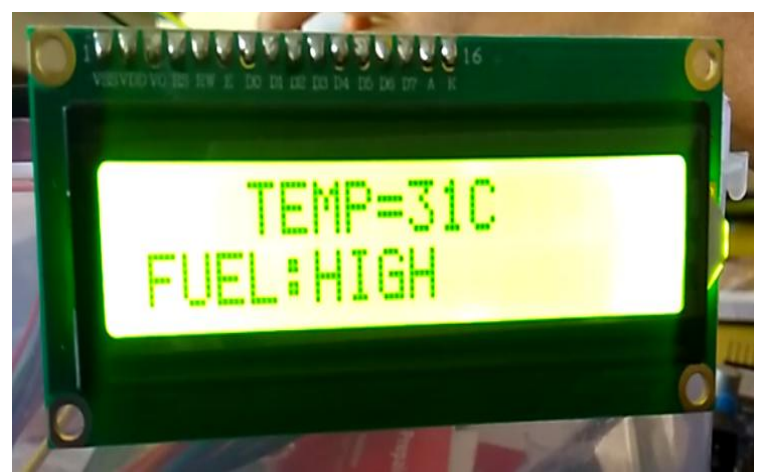

Fig. 5 Fuel level detection - High

When fuel level goes low then the system will display the message as "FUEL: LOW" with the indication of fuel level temperature also measured and displayed as shown in Fig. 6

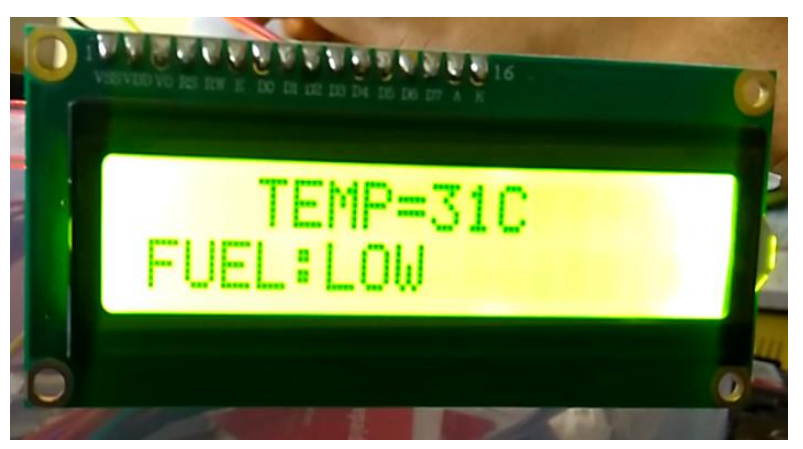

Fig. 6 Fuel level detection - Low

When any object is detected then "KEEP SAFE DIST" message getting displayed on the LCD Screen and for the indication purpose buzzer is $\mathrm{ON}$.

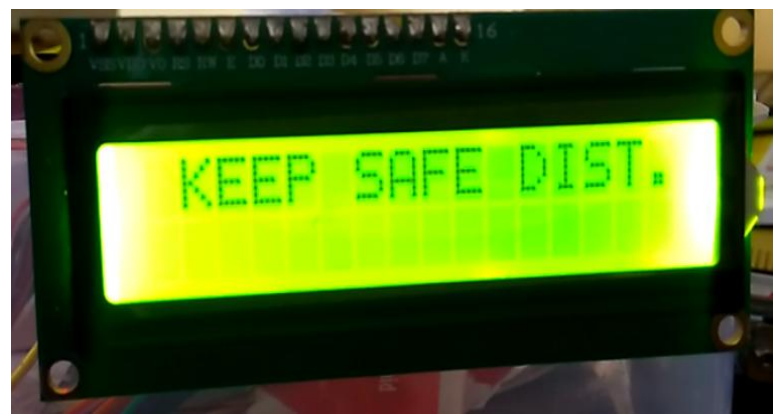

Fig. 7 Accident detection

To avoid situations like accident system provides alert to the driver to drive safe and sound for safety of all passenger and driver as shown in Fig. 7

Every time driver or any other vehicle users will not check the condition of tyres. Conditions like air pressure in the tyres etc.

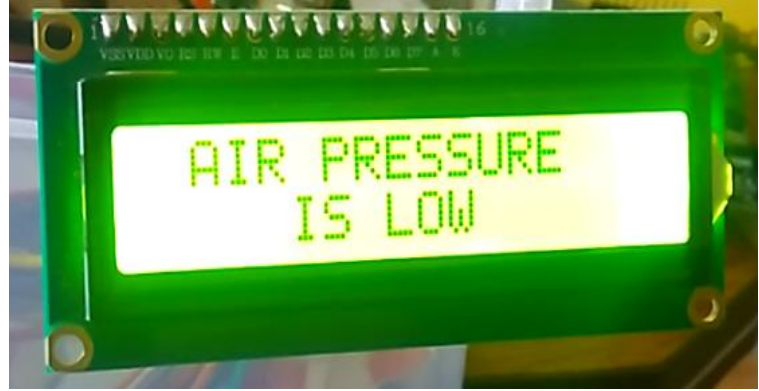

Fig. 8 Puncture detection

When air pressure goes low may cause some critical conditions and driver will not recognize immediately about this condition, so system provide puncture detection facility. When air pressure goes low then system display the message on LCD Screen as "AIR PRESSURE IS LOW" as shown in Fig. 8

\section{Part B: At the authorized user side}

At the authorized user side Smartphone Enabled Advanced Vehicle Tracking app. is present. With the help of this app authorized person can track his vehicle at any time by giving just a Missed Call. He will find the exact location of vehicle within few minutes. Fig. 4.7 shows the User Interface (UI) of the App.

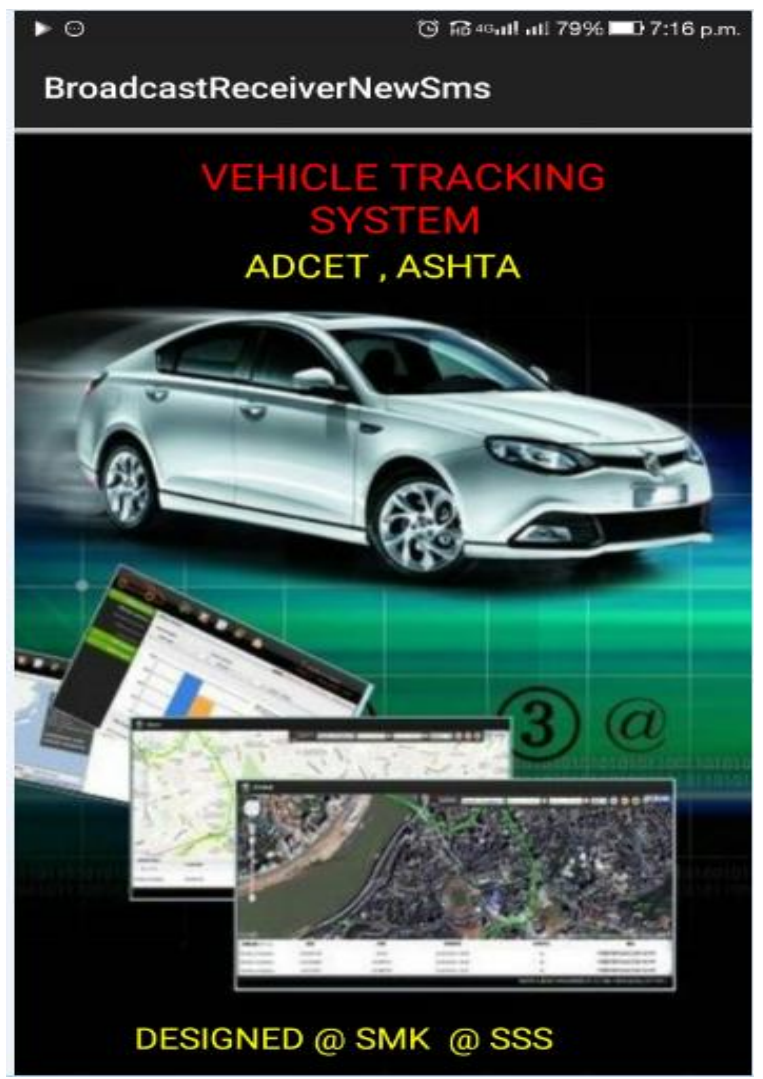

Fig. 9 User Interface of App 


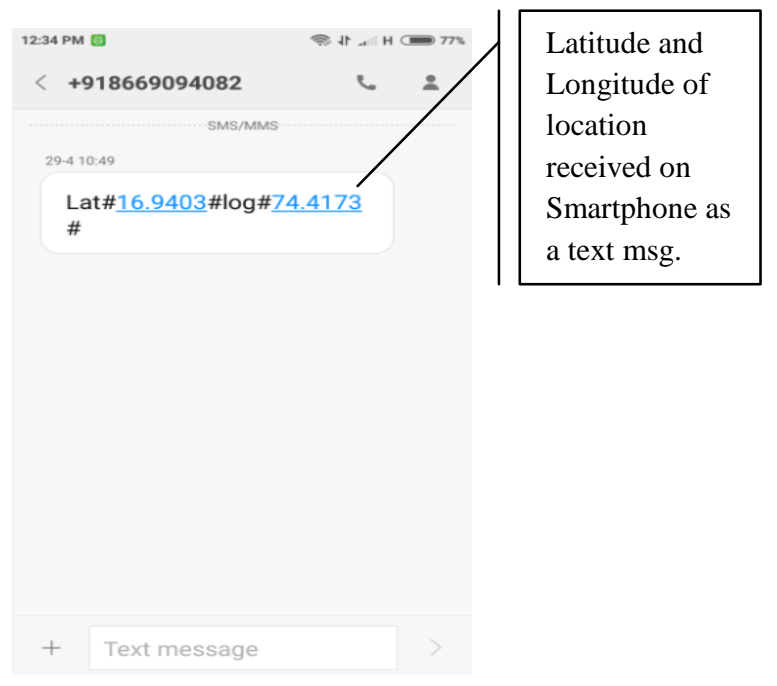

Fig. 10 Text message window

When authorized person give a missed call to the GSM in the vehicle, then vehicle give response through GPS. With the help of GPS coordinates of the location, these coordinates send towards the authorized person in the text message format. Fig. 10 shows text message window when authorized person receives a coordinates of the location.

At the time when authorized person receives the coordinates in text message form, these coordinates get extracted automatically in the Smartphone Enabled Advanced Vehicle Tracking app.

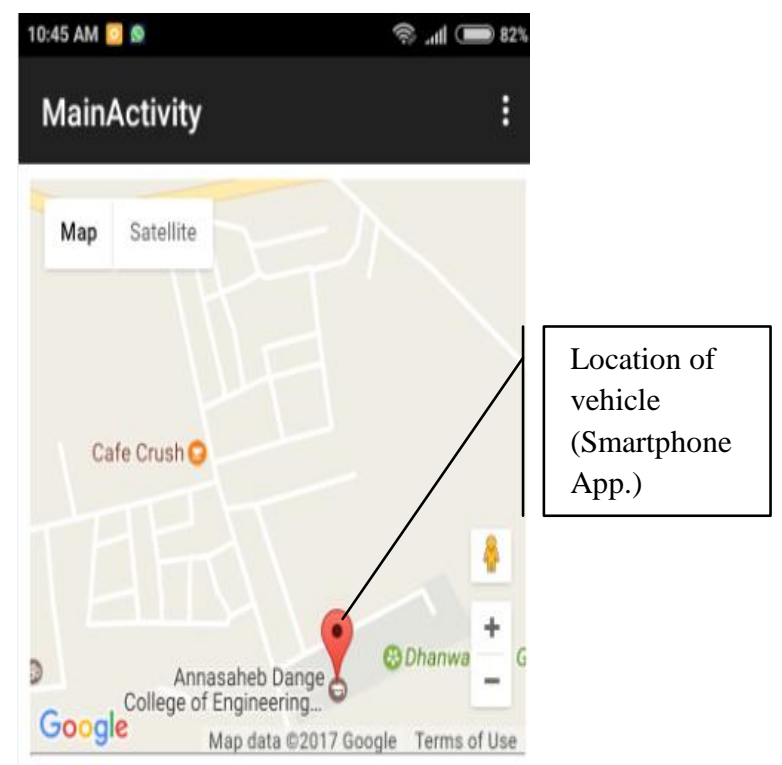

\section{Marker status:}

Current position:

$16.9403,74.41730000000007$

Closest matching address:

Unnamed Road, Anand Colony, Ashta,

Maharashtra 416301, India

Fig. 10_a Location of vehicle on Google Map
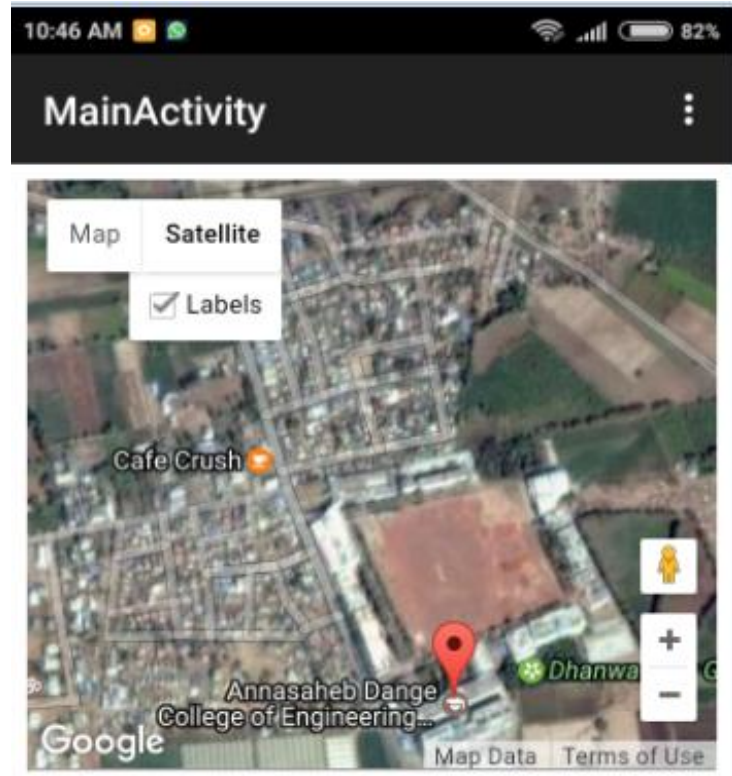

\section{Marker status: \\ Current position: \\ 16.9403, 74.41730000000007 \\ Closest matching address: \\ Unnamed Road, Anand Colony, Ashta, \\ Maharashtra 416301, India}

Fig. 10_b Location of vehicle on Satellite

Table 1 shows the experimental real time results of the system. With reference to the Table1, locations of the vehicles received on the Smartphone app are nearly close to the locations searched on Google map.

Time wastage manually calculated when authorized user wants to check that vehicle waste time anywhere in travelling. Then he gave missed call two times to vehicle and checks the location details and time. 
Table 1 Real time results

\begin{tabular}{|c|c|c|c|c|c|c|c|c|c|}
\hline \multirow{2}{*}{$\begin{array}{l}\text { Sr. } \\
\text { No }\end{array}$} & \multirow{2}{*}{$\begin{array}{c}\text { User } \\
\text { Number }\end{array}$} & \multirow{2}{*}{$\begin{array}{l}\text { Response } \\
\text { Number }\end{array}$} & \multicolumn{2}{|c|}{ Time } & \multicolumn{2}{|c|}{$\begin{array}{l}\text { Actual Location } \\
\text { (Google) }\end{array}$} & \multicolumn{2}{|c|}{$\begin{array}{c}\text { Location Information } \\
\text { received through } \\
\text { SMS }\end{array}$} & \multirow{2}{*}{ App Location } \\
\hline & & & $\begin{array}{c}\text { Missed } \\
\text { call } \\
\text { given }\end{array}$ & $\begin{array}{c}\text { SMS } \\
\text { Received }\end{array}$ & Latitude & Longitude & Latitude & $\begin{array}{l}\text { Longitud } \\
\mathrm{e}\end{array}$ & \\
\hline 1 & 8956367577 & 9112632623 & $\begin{array}{c}3: 23: 30 \\
\text { PM }\end{array}$ & $\begin{array}{c}3: 23: 50 \\
\text { PM }\end{array}$ & 17.0500 & 74.2652 & 17.0500 & 74.2652 & $\begin{array}{l}\text { Gandhi Chowk, Urun } \\
\text { Islampur, } \\
\text { Maharashtra } \\
\text { 415409,India }\end{array}$ \\
\hline 2 & 8956367577 & 9112632623 & $\begin{array}{c}3: 24: 20 \\
\text { PM }\end{array}$ & $\begin{array}{c}3: 24: 35 \\
\text { PM }\end{array}$ & 17.0636 & 74.2832 & 17.0636 & 74.283199 & $\begin{array}{l}\text { RIT,Rajaramnagar, } \\
\text { UrunIslampur, } \\
\text { Maharashtra } \\
\text { 415409,India }\end{array}$ \\
\hline 3 & 8956367577 & 9112632623 & $\begin{array}{c}3: 25: 30 \\
\mathrm{PM}\end{array}$ & $\begin{array}{c}3: 25: 45 \\
\text { PM }\end{array}$ & 18.9303 & 73.9252 & 18.9303 & 73.925200 & $\begin{array}{l}\text { Sai Anand } \\
\text { Bekary,Peth Rd, } \\
\text { Peth, Maharashtra } \\
\text { 410512, India } \\
\end{array}$ \\
\hline 4 & 8956367577 & 9112632623 & $\begin{array}{c}3: 23: 15 \\
\text { PM }\end{array}$ & $\begin{array}{c}3: 23: 30 \\
\text { PM }\end{array}$ & 16.9403 & 74.4173 & 16.94033 & 74.4173 & $\begin{array}{l}\text { ADCET, Ashta, } \\
\text { Maharashtra 416301, } \\
\text { India }\end{array}$ \\
\hline 5 & 8956367577 & 9112632623 & $\begin{array}{c}\text { 9:13:00 } \\
\text { AM }\end{array}$ & $\begin{array}{c}\text { 9:13:09 } \\
\text { AM }\end{array}$ & 17.2830 & 74.1829 & 17.2830 & 74.1829 & $\begin{array}{l}\text { East of Bus Stand, } \\
\text { Karad,Maharashtra } \\
\text { 415110,India }\end{array}$ \\
\hline 6 & 8956367577 & 9112632623 & $\begin{array}{l}9: 11: 0 \\
5 \mathrm{AM}\end{array}$ & $\begin{array}{c}9: 11: 06 \\
\text { AM }\end{array}$ & 17.6932 & 74.0043 & 17.6926 & 74.00469 & $\begin{array}{l}\text { SH 58, Koyana } \\
\text { Nagar, Satara, } \\
\text { Maharashtra } \\
\text { 415001,India }\end{array}$ \\
\hline 7 & 8956367577 & 9112632623 & $\begin{array}{c}9: 09: 10 \\
\text { AM }\end{array}$ & $\begin{array}{c}9: 09: 15 \\
\text { AM }\end{array}$ & 18.5018 & 73.8636 & 18.5018 & 73.8636 & $\begin{array}{l}\text { 485, Maharana } \\
\text { Pratap Singh Rd, } \\
\text { Ghorpade Peth, } \\
\text { Swargate,Pune,Maha } \\
\text { rashtra 411042,India }\end{array}$ \\
\hline
\end{tabular}

\section{Part C: At the monitor side}

The information of location saved in database for a record. When, in future the authorized person needs any location information about vehicle by using database user can search easily. Data recorded in the form of date, time and location. Table 2 shows the detailed information of database management.

Table 2 Database management

\begin{tabular}{|c|c|c|c|}
\hline Sr.No. & Date & Tmie & Latitude \& Longitude \\
\hline 1 & $12 / 10 / 2016$ & $3: 23: 50 \mathrm{PM}$ & Lat\#17.0500\#log\#74.2652\# \\
\hline 2 & $12 / 25 / 2016$ & $3: 24: 35 \mathrm{PM}$ & Lat\#17.0636\#log\#74.283199\# \\
\hline 3 & $1 / 10 / 2017$ & $3: 25: 45 \mathrm{PM}$ & Lat\#18.9303\#log\#73.925200\# \\
\hline 4 & $1 / 21 / 2017$ & $3: 23: 30 \mathrm{PM}$ & Lat\#16.94033\#log\#74.4173\# \\
\hline 5 & $2 / 4 / 2017$ & $9: 13: 09 \mathrm{AM}$ & Lat\#17.2830\#log\#74.1829\# \\
\hline 6 & $2 / 15 / 2017$ & $9: 11: 06 \mathrm{AM}$ & Lat\#17.6926\#log\#74.00469\# \\
\hline 7 & $2 / 27 / 2017$ & $9: 09: 15 \mathrm{AM}$ & Lat\#18.5018\#log\#73.8636\# \\
\hline
\end{tabular}

\section{ACKNOWLEDGMENTS}

Our thanks to the department of Electronics \& Telecommunication, Annasaheb Dange College of
Engineering and Technology, Ashta, Maharashtra, India, for suggesting the line of research. 


\section{REFERENCES}

[1] SeokJu Lee. "Design and Implementation of Vehicle Tracking System Using GPS/GSM/GPRS Technology and Smartphone Application", IEEE World Forum on Internet of Things (WF - IoT),2014.

[2] Suraj Patinge. "Design of ARM Based Data Acquisition \& Control Using GSM \& TCP/IP Network", IEEE International Conference on Computational Intelligence and Computing Research, 2013.

[3] Pham Hoang Oat. "Development of Vehicle Tracking System using GPS and GSM Modem", IEEE conference on Open Systems (ICOS), December 2-4,2013, Sarawak Malaysia,2013.

[4] B.Janarthanan, "Real time metropolitan bus positioning system design using GPS and GSM"

[5] Dalip and Vijay Kumar, "GPS and GSM based Passenger Tracking System", International Journal of Computer Applicatins (0975-8887) Volume 100 -No.2, August 2014.

[6] Vigneshwaran. K, and et.al, "An Intelligent Tracking System Based on GSM and GPS Using Smartphones", Vol. 4, Issue 5, May 2015, International Journal of Advanced Research in Electrical, Electronics and Instrumentation Engineering, May 2015.

[7] Guido Albertengo, and et.al, "Smartphone based connected vehicles pave the way to intelligent mobility", WTC 2014 (World Telecommunications Congress 2014)
[8] Garima Pandey, Diksha Dani, "Android Mobile Application Build on Eclipse", International Journal of Scientific and Research Publications Volume 4, Issue 2, February 2014, ISSN 2250-3153

[9] S. Sivasubramanian and et.al, "A Proposed Android Based Mobile application to Monitor Works at Remote Sites", International Journal of Science and Research (IJSR) ISSN (online): 2319-7064

[10] Amol Dhumal and et.al, "Vehicle Tracking System Using GPS and Android OS", International Journal of Advanced Research in Computer Engineering \& Technology (IJARCET) Volume 4 Issue 4, April 2015

[11] S. Priya and et.al, "An Android Application for Tracking College Bus Using Google Map", International Journal of Computer Science and Engineering Communications Vol.3, Issue 3, 2015, Page 1057-1061, ISSN: 2347-8586

[12] Deepa V. Jose and et.al, "Challenges and Issues in Android App Development - An Overview”, International Journal of Advanced Research in Computer Science and Software Engineering, Volume 5, Issue 1, January 2015, ISSN: 2277 128X

[13] Internet sources https://en.wikipedia.org/wiki/Global_Positioning_System https://www.arduino.cc/en/main/arduinoBoardUno

https://www.elprocus.com/infrared-ir-sensor-circuit-andworking/

https://en.wikipedia.org/wiki/GSM 